\title{
MATERIAIS EDUCACIONAIS DIGITAIS: UMA ANÁLISE SOB A PERSPECTIVA DOS TUTORES NA EAD
}

\author{
Digital educational materials: an analysis under the perspective of the tutors in the ead
}

\section{Dayane Da Silva Rodrigues De Souza ${ }^{1}$ Bruno César Dias De Albuquerque ${ }^{2}$ Zélia Maria Soares Jófilii}

\begin{abstract}
RESUMO: A educação a distância - EAD se destaca por utilizar a tecnologia a favor da realização do seu processo de ensino aprendizagem, dessa forma os materiais educacionais digitais - MED fazem parte deste cenário oferecendo um suporte tecnológico e pedagógico eficiente e motivador para os profissionais e alunos, assim, por compreender a importância deste suporte na educação, esta pesquisa analisou o uso dos MED sob a perspectiva dos tutores da EAD do Instituto Federal do Piauí- IFPI. Este estudo tem um paradigma qualitativo, e utilizou o questionário como instrumento de pesquisa, no qual foi possível identificar a importância dos MED, a necessidade de otimização dos materiais digitais utilizados e de formação especifica para uso deles, além de destacar possibilidades de expansão desses materiais.
\end{abstract}

Palavras-chaves: Educação a Distância, IFPI, Materiais Educacionais Digitais - MED, suporte tecnológico, tutores.

ABSTRACT: The Distance education - EAD stands out because it uses technology in favor of its teaching learning process, so the digital educational materials - MED are part of this scenario, offering an efficient and motivational technological and pedagogical support for EAD professionals and students, Therefore, in order to understand the importance of this support in education, this research analyzed the use of the MED from the perspective of the tutors of the EAD of the Institute Federal of Piaui - IFPI. This study has a qualitative paradigm, and used the questionnaire as a research tool, in which it was possible to identify the importance of the MED, the need for optimization of the digital materials used and the specific training for their use, besides highlighting possibilities of expansion of these materials

Keywords: Distance Education, IFPI, Digital Educational Materials - DEM, technological support, tutors.

\section{INTRODUÇÃO}

Atualmente vivemos em uma sociedade permeada de vários recursos tecnológicos em todos os aspectos da vida cotidiana e os processos que permitem as trocas de informações estão cada vez mais sofisticados, evoluídos e rápidos, “com isso, vê-se um aperfeiçoamento tecnológico que facilita a vida dos indivíduos que atuam na sociedade atual, na qual o tempo é precioso" (CUNHA, et al., 2012, p 03).

Esse processo envolve não apenas aspectos e relações pessoais dos indivíduos, mas também apresenta relevantes impactos no contexto profissional e educacional. E dentro deste

\footnotetext{
1 Professora do Instituto Federal do Piauí - Campus Pedro II

2 Professor do Instituto Federal do Piauí - Campus Pedro II

3 Professora da Universidade Federal Rural De Pernambuco
} 
cenário, a educação a distância se destaca por usar a tecnologia a seu favor, buscando inovações na forma de ensinar e aprender, incluindo recursos que antes não eram utilizados neste processo, buscando uma comunicação mais eficaz e, consequentemente, resultados positivos no processo de ensino-aprendizagem.

Uma das estratégias incluídas no processo de ensino na EAD foram materiais educacionais digitais- MED, os quais podem ser considerados qualquer material que tenha um objetivo educacional e que inclua recursos tecnológicos para sua apresentação e desenvolvimento.

Portanto, os materiais educacionais podem se apresentar em diferentes formas, através das mídias, assim podemos consideram MED, os vídeos, simulações, jogos, softwares, e-book, guias de estudo, dentre vários outros. Para produção dos MED pode se utilizar processos simples, até estruturas mais complexas.

Contudo, para muitos docentes (professores e tutores), a produção destes MED ainda não é uma tarefa fácil, e muitas vezes exigem conhecimentos diferenciados sobre manuseio de tecnologias que nem todos os docentes possuem, dificultando assim a utilização de forma mais eficiente dos materiais digitais, além disso, a escolha de materiais digitais que já estão prontos também representa um desafio.

Percebendo esse desafio educacional, este artigo busca analisar o uso de Materiais Digitais Educacionais sob a perspectiva dos tutores durante o seu trabalho docente na EAD, do IFPI, concomitantemente, esta pesquisa busca identificar o perfil dos professores, as limitações e dificuldades encontradas por eles no uso dos MED, assim como possivelmente identificar possibilidades que podem trazer uma maior eficiência para a utilização dos MED na EAD.

\section{METODOLOGIA}

Este estudo é qualitativo, pois busca um entendimento aprofundado de um determinado fato dentro de uma instituição, buscando uma interpretação do cenário, atual, dos acontecimentos, pois Martins (2004, p. 292) esclarece que:

[...] as metodologias qualitativas privilegiam, de modo geral, a análise de microprocessos, através do estudo das ações sociais individuais e grupais. Realizando um exame intensivo dos dados, tanto em amplitude quanto em profundidade, os métodos qualitativos tratam as unidades sociais investigadas como totalidades que desafiam o pesquisador (MARTINS, 2004, p. 292).

Esta pesquisa, também, possui características de uma pesquisa exploratória, que conforme Severino (2007) refere-se a um levantamento de informações sobre um determinado objeto, havendo uma delimitação do campo de trabalho, e mapeamento das condições e manifestações do objeto da pesquisa. O paradigma exploratório também está presente em estudos “que têm por 
objetivo familiarizar-se com o fenômeno ou obter uma nova percepção dele e descobrir novas ideias". (CERVO, BERVIAN E DA SILVA, 2007, p.63).

A pesquisa tem como participantes tutores (presenciais e virtuais), do curso Técnico em Administração, do Instituto Federal de Educação do Piauí- IFPI, que começou em 2014 e finalizou em 2016, estas turmas estão situadas nos campi de Cocal, Paulistana e Pedro II. Desta forma, a pesquisa conseguiu abranger profissionais que se encontram em diversos campi, de norte a sul do estado do Piauí, e assim retratará de forma mais ampla a situação geral do objeto da pesquisa no ensino a distância no IFPI.

Como o IFPI possuía 19 cursos técnicos na época da realização da pesquisa, na modalidade EAD, tornando-se um campo muito amplo de aplicação do estudo, o curso técnico em administração foi escolhido, inicialmente por que é um dos cursos da área de gestão e negócio, conforme o Catálogo Nacional de Cursos Técnicos, e dentre os cursos desta área que oferecemos: Administração, serviços jurídicos e serviços de condomínio, o curso de administração é o que possui uma maior abrangência no mercado, em relação a postos de trabalho, e que atualmente, no estado do Piauí tem grande importância para o desenvolvimento socioeconômico da região, e também por ser a área de formação e atuação da autora desta pesquisa, que assim poderia ter mais afinidade e conhecimento sobre o objeto da pesquisa.

Os participantes foram convidados presencialmente e por email, a responderem o questionário disponibilizado, impresso e virtualmente.

O questionário, instrumento de pesquisa utilizado, é um método que se refere a um meio de coletar informações, obtendo respostas às questões formuladas pelo pesquisador, que tomará por base o problema central, para a produção do instrumento (CERVO; BERVIAN E DA SILVA, 2007). O método conteve questões mistas, algumas objetivas e outras subjetivas, abertas, "que permitem ao participante responder livremente, usando linguagem própria, e emitir opiniões" (MARCONI E LAKATOS, 2010, p.187), a fim de que se encontrasse o máximo de situações, problemas e ao mesmo tempo soluções.

Todos os voluntários que concordaram com a participação na pesquisa assinaram um Termo de Consentimento Livre e Esclarecido (TCLE), contendo a descrição dos objetivos da pesquisa e a garantia de confidencialidade.

\section{REFERENCIAL TEÓRICO}

Materiais educacionais digitais - conceitos e contextualização 
O contexto no qual estudamos os MED nesta pesquisa é a Educação a Distância, a qual reconhecemos como um processo de ensino-aprendizagem, no qual alunos, professores, equipe pedagógica e administrativa encontram-se distantes fisicamente e geograficamente, na maior parte do desenvolvimento do curso, mas que utilizam vários suportes, dentre eles a tecnologia, para efetivação da mediação da comunicação e interação entre os atores deste processo, com o objetivo de promover a construção de conhecimentos e a formação de profissionais.

Compreendendo que a inserção e uso das TIC- Tecnologias de Informação e Comunicação no ambiente educacional facilita a construção do conhecimento com o suporte de variadas formas e mídias, reconhecemos os materiais educacionais digitais são ferramentas que oferecem métodos de transmissão de conteúdos educacionais de forma diferenciada, interativa e criativa que contribuem para uma diversificação do processo educacional.

$\mathrm{Na}$ educação baseada em tecnologias interativas, diversas novas mídias, com características diferentes das tradicionais, se incorporam ao rol de opções oferecidas aos educadores. Entre as características dessas novas mídias destacam-se: formato digital; grande número de formatos e padrões para uma mesma mídia; os custos de produção variam de quase zero à casa dos milhões; podem ser criadas com equipamentos caseiros, mas para uma produção profissional exigem equipamentos e mão-de-obra sofisticados; podem ser produzidas e editadas tanto industrial quanto artesanalmente. (TORI, 2010, p.109).

Os materiais educacionais digitais- MED referem-se a "todo material didático elaborado com objetivos relacionados à aprendizagem e que incorpora recursos digitais" (BEHAR, 2009, p.33), podendo ser representado em diversos formatos, cada um com suas especificidades relativas ás práticas pedagógicas.

Da mesma forma, Falkembach (2005) considera materiais educativos digitais "recursos que podem ser desde pequenas atividades realizadas via computador ou ainda livros eletrônicos, jogos, simulações, histórias em quadrinhos ou desafios propostos aos alunos" (FALKEMBACH, 2005, p.02). Assim, podemos perceber a diversidade com a qual os MED podem se apresentar, sendo que essa variedade pode favorecer uma maior motivação dos participantes do processo de ensino-aprendizagem e, concomitantemente, a construção do conhecimento.

Nesta pesquisa os MED são considerados como representações de qualquer material didático, produzido para atender uma necessidade pedagógica, que apresenta um conteúdo e tem o objetivo de gerar conhecimento, mas com o diferencial de que em sua concepção ou forma de apresentação utiliza os recursos digitais, assim muitas vezes nesta pesquisa utilizaremos o termo "recurso digital" ou "recurso tecnológico" para referir-nos a um elemento que compõem o material digital.

\section{O PAPEL DO TUTOR NA EDUCAÇÃO A DISTÂNCIA}


Conforme Mill et.al, (2010) o conceito de docência na EAD, é um fenômeno muito complexo, pois deve levar em consideração o contexto individual, social e histórico em que está inserido. E por isso é importante enfatizar que o trabalho docente na EAD é um processo coletivo, no qual existe uma interdependência dos atores que fazem parte desta educação, e observando assim essa atividade sob uma perspectiva ampla, podemos considerar o conceito de Mill et. al (2010) sobre a polidocência na EAD:

[...] quando consideramos a docência na EAD como polidocência estamos entendendoa como uma categoria profissional que extrapola o fazer pedagógico, para além de categoria professoral. Desta forma, não apenas os professores responsáveis pelo conteúdo devem ser considerados docentes na EAD, mas também aqueles que acompanham os estudantes e aqueles que organizam pedagogicamente os conteúdos dos materiais didáticos. Os novos desafios impostos pelas tecnologias ao processo de ensino aprendizagem, apesar de muitas vezes criarem divergências e medo entre os educadores, também trouxeram muitas vantagens, e em alguns casos provocou uma mudança radical nos processos e metodologias. (MILL et. al., 2010, p.20)

Levando em consideração o conceito de Mill et. al. (2010), consideramos que tanto o professor (autor, pesquisador, etc.) quanto o tutor (virtual e presencial), ou até mesmo outro profissional que faça parte do processo de ensino-aprendizagem, auxiliando os alunos no desenvolvimento das disciplinas e do conteúdo, podem ser considerados docentes na EAD. E dessa forma, podemos observar que o professor possui uma grande responsabilidade pela identificação das necessidades dos estudantes, aplicação das metodologias e recursos mais adequados, e pela construção do conhecimento.

Especificamente sobre tutores um estudo muito importante realizado pelas autoras Ricieri e Gitahy (2012) enfatizou a importância da formação do tutor para atuação na EAD, e mostrou que tutores preparados contribuem significativamente para o alcance dos objetivos almejados pela Instituição, concluindo que diante do cenário de constantes mudanças que vivemos atualmente estes profissionais necessitam estar sempre preparados e capacitados para lidar com as diversas situações do cotidiano exigidas pela EAD.

Assim, podemos perceber que o educador na EAD convive dentro de um sistema que necessita da sua preparação para lidar com diversos contextos e situações, sempre buscando contribuir para que o estudante consiga construir o conhecimento, pois:

[...] ensinar em ambientes digitais e interativos de aprendizagem significa: organizar situações de aprendizagem, planejar e propor atividades; disponibilizar materiais de apoio com o uso de múltiplas mídias e linguagens; ter um professor que atue como mediador e orientador do aluno, procurando identificar suas representações de pensamento; fornecer informações relevantes, incentivar a busca de distintas fontes de informações e a realização de experimentações; provocar a reflexão sobre processos e produtos; favorecer a formalização de conceitos; propiciar a interaprendizagem e a aprendizagem significativa do aluno (ALMEIDA, 2003, p.333). 
Dessa forma, podemos compreender que no processo de ensino e aprendizagem o educador deverá ser capaz de atender às demandas de seu público no contexto que lhe é colocado, deve buscar, constantemente, qualificação e preparação para atuar na sua função com o máximo de eficiência, pois cada vez mais será exigida, essa competência, tanto por parte da instituição quanto pelos estudantes.

[...] tais exigências solicitam do professor a aquisição de novos conhecimentos novas habilidades e novos métodos de ensino. Sob essas condições, elas requerem um processo intenso de capacitação, fundamentado na motivação, na cooperação e na pesquisa, em que a utilização crítica da informação e das tecnologias, habilidades de pesquisa e comunicação são fundamentais para o exercício de ensinar, principalmente, para o professor de educação a distância”. (AMARILLIA FILHO, 2011, p. 54).

Com a constante evolução das tecnologias, estas exigências se tornaram cada vez maior, pois a tecnologia hoje é um fator fundamental na educação, e a utilização dos seus diversos recursos tem se tornado cada vez mais desafiante aos educadores (CANTINI, 2006), por isso conforme Minatti e Tomé (2012) o processo de capacitação e preparação destes educadores é essencial e deve contemplar o processo geral da EAD, e também enfatizar o uso das tecnologias e de seus recursos no ambiente escolar, visando um uso mais adequado e produtivo destas ferramentas, enfatizando suas vantagens e conscientizando seus usuários sobre os possíveis prejuízos pelo seu mau uso.

\section{MED - UM DESAFIO EDUCACIONAL}

Por sua enorme variedade e importância no processo educativo, os materiais educacionais digitais devem sem cuidadosamente analisados e escolhidos para uso, levando em consideração o objetivo, a adequação ao contexto, ao aluno, ao ambiente e à metodologia adotada. “[...] vídeos, programas educativos na televisão e no computador, sites educacionais, softwares diferenciados transformam a realidade da aula tradicional, dinamizam o espaço de ensino-aprendizagem" (KENSKI, 2007, p.46). Porém, para que realmente existam resultados positivos e que este processo faça alguma diferença para o processo educativo é necessário que exista o respeito às especificidades do ensino e da própria tecnologia.

\footnotetext{
Mais importante que as tecnologias, que os procedimentos pedagógicos modernos, no meio de todos esses movimentos e equipamentos, o que vai fazer a diferença qualitativa é a capacidade de adequação do processo educacional aos objetivos que levaram você, pessoa, usuário, leitor, aluno, ao encontro desse desafio de aprender. (KENSKI, 2007, p.46).
}

Atualmente, um dos grandes desafios docente é o aproveitamento integral dos recursos 
que essas tecnologias possibilitam, pois o uso destes recursos tecnológicos ainda estar aquém do seu potencial, por diversos motivos, dentre eles pela falta de formação docente, pela falta de propriedade, ou até mesmo pela indisponibilidade dos educadores em buscar novos conhecimentos, dessa forma os recursos que poderiam ser implementados no material digital acabam sendo subutilizados e dificultando a geração de um impacto positivo no ambiente educativo.

\footnotetext{
$\mathrm{Na}$ sociedade da informação todos estamos reaprendendo a conhecer, a comunicar-nos, a ensinar e a aprender; a integrar o humano e o tecnológico; a integrar o individual, o grupal e o social. Uma mudança qualitativa no processo de ensino/aprendizagem acontece quando conseguimos integrar dentro de uma visão inovadora todas as tecnologias: as telemáticas, as audiovisuais, as textuais, as orais, musicais, lúdicas e corporais. Passamos muito rapidamente do livro para a televisão e vídeo e destes para o computador e a Internet, sem aprender e explorar todas as possibilidades de cada meio. (MORAN, 2000).
}

Nesse contexto, a educação a distância possui uma enorme vantagem, já que na maioria das vezes acontece utilizando os recursos da TIC, mais propriamente a internet, e utilizam ambientes virtuais para administrar as pessoas e informações envolvidas neste processo. Com isso, a educação a distância tem em seu ambiente educacional inúmeras possibilidades com o uso das tecnologias, e pode criar e utilizar variados materiais educacionais digitais e disponibilizá-los em sua plataforma, ou em ambientes desenvolvidos ou adaptados para a aprendizagem.

Contudo, ainda existem muitos desafios relacionados ao uso dos materiais digitais pelos educadores, dentre eles a falta de diversificação dos materiais e recursos utilizados, tornando o ambiente de aprendizagem desinteressante. Dessa forma Wolynec (2006, apud ARAÚJO, 2007, p. 5) afirma que "para desenvolver o conhecimento, é necessário um ambiente de aprendizagem muito mais rico e diversificado do que o utilizado para a simples transmissão de informação".

Existe também outro obstáculo significativo quanto ao uso dos materiais digitais que se referem à criação destes, pois muitos dos educadores não têm uma capacitação para utilizar e elaborar recursos digitais e, além disso, ainda desconhecem os repositórios que podem ajudá-los fornecendo materiais que já estão prontos para utilização (SOUZA, 2016).

Com isso percebemos que os desafios não estão apenas na criação dos materiais educacionais digitais, mas muito além disso, englobando desde a falta de uma formação adequada, limitações, baixa qualidade dos MED, até a disponibilização de uma estrutura de rede que supra a necessidade da comunidade acadêmica de um curso na EAD.

\section{RESULTADOS}


Com a aplicação dos questionários com os tutores presenciais e virtuais do curso Técnico em Administração, do IFPI, foi possível encontrar e relacionar algumas informações relevantes para a conclusão desta pesquisa.

\section{Perfil dos tutores}

Inicialmente foi analisado o perfil dos tutores, e verificou-se que 02 tutores possuem entre 26 e 30 anos, e 03 tutores possuem mais de 31 anos, sendo destes duas pessoas do sexo feminino e 03 do sexo masculino, agregando maior diversificação e inclusão de ambos os gêneros. Quanto á formação destes tutores, é possível observar no quadro abaixo:

\section{Quadro 1: Formação dos tutores do Curso Técnico em Administração}

\begin{tabular}{|l|c|}
\hline \multicolumn{1}{|c|}{ Formação acadêmica } & Quantidade de tutores \\
\hline Bacharelado em Administração. & 02 \\
\hline Bacharelado em Administração e Gestão em Recursos Humanos. & 01 \\
\hline Bacharelado em Administração; Licenciatura em Filosofia e em Sociologia. & 01 \\
\hline Bacharelado em Administração, com especialização em Gestão de Pessoas. & 01 \\
\hline
\end{tabular}

Fonte: Dados coletados pela autora (2016)

Através dos dados coletados observou-se que os tutores possuem formação na área em que atuam, e muitos deles possuem outras formações e complementações, como pós-graduação. Estes dados são reflexos da exigência feita nas seleções, relativas à formação na área do curso que irão atuar, o que é muito importante e essencial, pois os tutores irão auxiliar os alunos nas suas atividades, e tirar dúvidas em relação aos conteúdos disponibilizados na plataforma necessitando para isso de competências conceituais, porém, além dessas habilidades "este profissional deve apresentar, ainda, alguns atributos, tais como: possuir clara concepção de aprendizagem, estabelecer relações empáticas, dominar o conteúdo, facilitar a construção do conhecimento" (FARIAS, 2010, p.31), que só poderão ser trabalhadas com uma orientação específica para atuar na EAD.

Nesta pesquisa também foi identificado que 03 tutores têm apenas experiência na EAD do IFPI, sendo que destes um atua a menos de um ano na EAD do IFPI, e 02 tutores possuem entre um e dois anos de experiência na EAD do IFPI, esse fator demonstra que a instituição deve observar estes perfis e buscar preparar estas pessoas que nunca atuaram ou que atuaram pouco tempo na educação a distância, pois embora muitas delas possam ter experiência docente, a educação a distância requer habilidades e técnicas diferenciadas de trabalho (KENSKI, 2003). 
Ainda dentro dessa análise, foi observado que 2 tutores atuam há mais de três anos na EAD, e o mesmo período também na EAD do IFPI, mas que atuaram em outras instituições como UESPI (Universidade Estadual do Piauî) e UNOPAR (Universidade Norte do Paraná), demonstrando assim que também existem profissionais com uma experiência significativa.

Todos os tutores que estão em atuação no curso investigado, estão desde o começo do curso, em 2014, e assim já acompanharam os alunos em diversas disciplinas como: Metodologia em EAD, Fundamentos em Administração, Matemática Aplicada a Administração, Comunicação Empresarial, Contabilidade Básica, Introdução ao Direito, Organização - Sistemas e Métodos, Gestão de Materiais, Gestão de Marketing, Direito Empresarial, Economia e Mercado, Sistema de Informação Gerencial, Gestão da Produção e Qualidade, Gestão Financeira, Empreendedorismo, Gestão de Projetos, Meio Ambiente e Sustentabilidade.

Em relação ao acesso ao curso, foi constatado que todos os tutores possuem acesso a internet em casa, acessando na maioria das vezes o curso deste local. Também percebemos que aliado ao acesso em casa, 4 tutores acessam o curso também pela estrutura disponibilizada no próprio IFPI, e 2 tutores aproveitam momentos no trabalho para acompanhar as atividades do curso.

Alguns tutores ainda citaram que acompanham o curso através dos seus dispositivos tecnológicos, smartphone, por exemplo, com estrutura 3g de qualquer local. Este diagnóstico é interessante, pois nos mostra que os profissionais estão conectados cada vez mais com às tecnologias disponíveis.

\section{Utilização dos materiais educacionais digitais}

Nesta seção analisou-se a utilização dos MED pelos tutores, buscando compreender a satisfação dos tutores com os MED disponibilizados, suas limitações e dificuldades, a importância que os tutores dão a este assunto, a possibilidade de inclusão de outros materiais, além dos que são disponibilizados, conhecimento sobre repositórios e sobre outros MED que não são utilizados no curso, dentre outros assuntos pertinentes.

Com os dados coletados foi possível constatar que 03 tutores sentem-se satisfeitos com a qualidade dos materiais educacionais digitais utilizados para o desenvolvimento das disciplinas, pois conforme eles, os materiais:

Tutor 1: São preparados por excelentes profissionais e com uma linguagem e pesquisa atual.

Tutor 2: São adequados e atende a necessidade do curso;

Tutor 3: $\quad$ São adequados para a realização do curso. 
Essa informação é muito útil, pois demonstra que boa parte dos tutores considera que o material possui uma qualidade adequada para serem trabalhados com os alunos, e isso pode também possibilitar uma maior eficiência no trabalho dos tutores, pois conforme Corrêa (2013, p.129) o material "assume o papel de fio condutor, já que organiza o desenvolvimento e a dinâmica de todo o processo de ensino e aprendizagem".

Contudo, também foi observado que 1 tutor não se sente satisfeito com os materiais e 1 que diz se sentir satisfeitos ou insatisfeitos “em partes”, ou seja, em alguns pontos sente-se satisfeitos e em outros não. Conforme os tutores essa insatisfação se dar porque os materiais:

Tutor 4: Alguns ainda deixam a desejar.

Tutor 5: Muitas vezes o material é muito repetitivo e não esclarece as dúvidas do aluno.

Para manter a qualidade dos materiais e a satisfação dos seus usuários é importante que esses fatores sejam analisados periodicamente, pois os cenários mudam rapidamente, e são necessárias constantes alterações para melhor atender as demandas dos participantes e a eficiência do processo de ensino aprendizagem.

O material didático em EAD é o principal elemento de viabilidade do projeto e desenho pedagógico de um curso. Para tanto, avaliá-lo em suas diversas dimensões (técnica, estética, didática e comunicacional) torna-se fundamental, pois os resultados desse olhar sobre os materiais proporcionarão repensar e revisar desde pequenos detalhes até a concepção e a própria estrutura desses materiais, caso seja necessário. (CORRÊEA, 2013, p.135).

Apesar de nem todos os tutores estarem satisfeitos com a qualidade dos MED utilizados na EAD do IFPI, 100\% deles afirmam o uso dos materiais educacionais digitais é importante para a EAD, pois conforme os tutores:

Tutor 1: Os materiais suprem a falta do contato físico do professor eliminando as dívidas;

Tutor 2: $\quad$ Pois com a velocidade que as coisas acontecem atualmente não podemos nos ater somente ao material tradicional;

Tutor 3: Ficam mais ao alcance dos alunos

Tutor 4: São a forma de interação com os alunos e melhor internalizarão.

Tutor 5: É super importante para o ensino aprendizagem do aluno.

De fato, os materiais digitais, são, indiscutivelmente, importantes e quando tratamos de ensino a distância, essa ferramenta ganha uma relevância ainda maior, pois o processo de ensino aprendizagem na EAD necessita de um aparato tecnológico que dê suporte as atividades que devem ser realizadas, disponibilizando recursos capazes de proporcionar a construção do conhecimento, conforme já discutimos no referencial teórico desta pesquisa.

Para os tutores, normalmente já existem materiais digitais produzidos ou indicados pelos professores, que são disponibilizados na plataforma, assim a maioria dos tutores utilizam os materiais que já existem, podendo os tutores complementarem esses materiais. Dessa forma, na analise das possíveis dificuldades existentes no uso dos MED disponibilizados na plataforma, foi 
observado que 02 tutores afirmam não possuir dificuldades, e 03 tutores possuem dificuldades, e conforme eles essa dificuldade advém de vários fatores, dentre eles:

Tutor 1: Não. O que às vezes inviabiliza o uso dos materiais é a baixa qualidade da internet.

Tutor 2: $\quad$ Sim. O acesso dificultado devido à estrutura da internet em nossa região.

Tutor 3: Sim. Porque às vezes falha.

Tutor4: Sim. As apostilas são muito grandes, porém devem ser postadas por URL. Em algumas cidades a internet é muito lenta, gerando insatisfação no aluno, porque não consegue acessar o material.

Podemos observar que os tutores possuem uma dificuldade quanto ao uso dos MED, relacionado a um ponto bem específico que é a estrutura de rede de internet dos campi que atuam, principalmente no interior do estado, dificultando o acesso dos alunos e tutores à materiais que possuem uma extensão maior para realização de download, gerando assim a ineficiência de alguns materiais disponibilizados, pois estes não conseguem atender a demandas dos alunos em tempo hábil, e no momento que ele precisa.

Levando em consideração essa dificuldade no uso dos MED, o tutor, na realização de suas atividades, pode complementar os materiais já disponibilizados, ou mesmo proporcionar um material mais atualizado ou mais atraente, acessível e diversificado que possibilitem uma eficiência maior quanto à aprendizagem. Conforme Corrêa (2013, p.134) essa diversificação é um fator positivo e "oportuniza diferentes formas de disponibilização dos conteúdos por meio dos materiais didáticos, além de ampliar os caminhos de interação entre alunos e professor". (CORRÊA, 2013, p.134)

Contudo, foi identificado que somente 01 dos tutores que responderam a esta pesquisa faz o uso de outros materiais digitais, além dos que já são disponibilizados pelo IFPI, são eles: outros vídeos, notícias de jornais atualizadas, sites da internet, etc. Esta iniciativa é muito útil e conveniente, visto que demonstra uma preocupação constante de levar ao aluno materiais atualizados, que favoreçam a aprendizagem. Em consonância com o resultado anterior temos 04 tutores que utilizam apenas os materiais que já estão na plataforma.

Essas informações sugerem à instituição a necessidade disseminação de informações e orientações aos profissionais quanto à existência de outros recursos valiosos que podem ser trabalhados na complementação dos materiais disponibilizados, e que muitas vezes esses materiais complementares podem facilitar a aprendizagem e trazer novas perspectivas de reflexão sobre os assuntos trabalhados.

Para ajudar os educadores a diversificarem seus materiais, existem, atualmente, vários repositórios de materiais digitais, que são site na web "que contém recursos digitais úteis para a aprendizagem formal ou não formal, com mídias como textos, imagens estáticas (mapas, gráficos, 
desenhos, ou fotografias) ou animadas (vídeos, filmes), arquivos de som, e objetos de aprendizagem" (LITTO, 2010, p. 88),

Porém mesmo com essa colaboração tecnológica, 03 dos tutores participantes da pesquisa afirmam não conhecer nenhum repositório de materiais digitais, o que pode dificultar a procura por outros materiais que poderiam ser disponibilizados e colaborar significativamente para o processo de ensino e aprendizagem dos alunos. Essa resposta também nos faz refletir sobre o possível desconhecimento deste termo "repositórios", podendo assim demonstrar que há a possibilidade dos tutores conhecerem algum repositório, mas desconhecerem o termo utilizado. Apenas 01 tutor respondeu que conhecia os repositórios, e 01 tutor deixou a questão em branco.

Mesmo com um considerável desconhecimento entre os tutores dos repositórios, 100\% dos tutores responderam conhecer outros tipos de materiais e que gostariam de utilizá-los no desenvolvimento de suas disciplinas. Por exemplo, citaram as videoconferências, como ferramentas que enriqueceriam muito a EAD nos polos do interior, e que poderia gerar MED eficientes para desenvolvimento do processo de ensino aprendizagem.

Dessa forma, percebemos a importância do investimento em capacitação para estes profissionais, pois a partir do momento em que se conhecem novas possibilidades e há apropriação delas pode haver grandes possibilidades de inclusão destas no processo ensinoaprendizagem, mesmo com as dificuldades que fogem do controle destes profissionais (KENSKI, 2003).

A plataforma Moodle utilizada na EAD do IFPI é a principal ferramenta para transmissão de conteúdo, orientação, acompanhamento do aluno, gestão do curso e eliminação de dúvidas, dentre outras atividades. Porém, atualmente vivemos em um mundo rodeado de redes de comunicação atraentes e que conseguem alcançar inúmeras pessoas, por isso tentamos analisar se os tutores possuem conhecimentos acerca dessas novas tecnologias e se as utilizam em favor do processo educativo.

Constatamos que $100 \%$ dos tutores utilizam outras ferramentas aliadas à plataforma, e que algumas delas como o email, são bem comuns. Outras como whatsapp e redes sociais são adaptadas para o processo educativo e contribuem significativamente nessa rede de colaboração e compartilhamento de informações importantes para o desenvolvimento dos cursos EAD (LEKA E GRINKRAUT, 2014).

Com essa informação, podemos visualizar a existência de outras estratégias de comunicação já utilizadas e que devem ser levadas em consideração pela instituição e incentivadas, pois são ambientes onde existe contato com os alunos, e que pode ser colaborar de forma eficiente para o processo de ensino-aprendizagem. 


\section{Relação entre o uso dos MED e a formação dos tutores}

Uma formação específica para atuação na EAD é extremamente importante, visto que na EAD existem vários processos que a tornam diferente da educação presencial, exigindo o desenvolvimento de habilidades essenciais para o bom desenvolvimento do trabalho nessa modalidade, pois quando os profissionais possuem conhecimentos e experiências relevantes aplicadas a EAD a execução de suas atividades cotidianas se tornam mais fáceis e eficientes (LEITZKE et al., 2008).

Assim, nesta pesquisa identificou-se que 3 tutores já possuíam uma formação voltada para a EAD antes da atuação no IFPI, dois 02 deles fizeram curso de capacitação e um fez especialização voltada para a educação a distância. Tivemos também 2 tutores que afirmaram não ter nenhuma formação anterior ao ingresso no IFPI, observando assim uma necessidade da instituição ter estratégias de formação que auxiliem os tutores no desempenho eficiente de suas funções.

Como o foco desta pesquisa são os materiais educacionais digitais, também foi analisado se os tutores possuíam formação específica para o uso do MED, e assim verificou-se que 3 tutores afirmam já possuírem algum tipo de formação voltada para o uso de materiais digitais, fator que pode influenciar significativamente no desempenho e no desenvolvimento das atividades que demandem o uso de MED. Em oposição as respostas anteriores, 2 tutores responderam não possuir nenhum tipo de formação específica no uso de MED, mais uma vez confirmando a necessidade de se investir em capacitação para estes profissionais.

Como é sabido, a qualificação dos profissionais para atuação na EAD é extremamente importante, pois os professores precisam tomar seus lugares de agentes ativos nesse novo contexto, que engloba a tecnologia como ferramenta de comunicação e informação, construindo competências e colocando-as em prática, tornando o processo de ensino-aprendizado mais coerente com a realidade vivenciada (CANTINI et al., 2006).

Assim, o investimento em formação específica para aplicação na EAD é indispensável, já que é necessária uma apropriação tecnológica por parte dos educadores, e dessa forma, essas habilidades só poderão ser efetivadas quando realmente existirem iniciativas que busquem uma formação continuada nesta área, pois a atualização tecnológica é muito rápida e os recursos dependentes dela também se desenvolvem com a mesma velocidade.

Levando em consideração esse fator, foi percebido que o incentivo e investimento em formação específica para o uso dos materiais digitais ainda é muito pequeno no IFPI. Foi 
identificado que 4 tutores não participaram de nenhuma capacitação para utilização dos MED, enquanto apenas 1 tutor afirmou ter participado de um treinamento específico prático em laboratório de informática do IFPI, o que pode demonstrar que existiu alguma ação nesta área, mas pode ter sido muito restrita e não conseguiu abranger todos ou a maioria dos tutores que atuam no curso de administração e em outros cursos oferecidos pelo IFPI.

A partir desta análise e em concomitância com as outras informações coletadas por meio deste questionário fica bem clara a necessidade de qualificação desses profissionais. E que estas estratégias possam ser ampliadas de forma a abranger todos os profissionais que atuam nestas atividades fins relacionadas ao processo ensino-aprendizagem.

\begin{abstract}
Necessita-se, portanto, repensar os projetos atuais, propondo que cada instituição na modalidade EAD busque construir um modelo tutorial que atenda às especificidades locais e regionais, visando à construção de um ambiente adequado de trabalho, melhores salários, maior tempo de estudo e preparação desse profissional para que sua ação educativa seja absorvida e bem aproveitada pelo aluno, trazendo novos sentidos e significados que contribuirão para o sucesso de sua vida acadêmica, profissional e pessoal. (SCHLOSSER, 2010, p 08.)
\end{abstract}

Dessa forma, percebe-se que a formação dos profissionais em EAD se torna muito complexa, pois além dos conhecimentos relativos à área de atuação, também precisam adquirir conhecimentos acerca desta modalidade. Assim, várias questões são tratadas de forma particular na educação a distância e uma delas é o uso dos materiais digitais, essenciais nesta modalidade, por visarem contribuir para a aprendizagem.

Todos os tutores consideram importante a inserção deste assunto durante as formações docentes, conforme se verifica nos depoimentos a seguir:

Tutor 1: Sim, para familiarizar e orientar o uso destes materiais;

Tutor 2: Sim, porque quanto mais conhecimento, mais capacidade terá o tutor;

Tutor 3: Sim, pois contribuirão para melhorar o ensino aprendizado.

Como estratégia para apontar uma solução viável e que possa colaborar com o desenvolvimento da EAD e dos materiais digitais no IFPI, a análise a seguir buscou identificar como deveria ser introduzida essa temática na formação dos tutores, a partir das próprias opiniões dos profissionais.

A maioria dos tutores ( 3 tutores) acredita que um curso a distância seria muito bom para que pudessem adquirir conhecimentos relativos aos materiais digitais. Seguido de 2 tutores que também acham interessante um manual sobre materiais digitais para auxílio na sua formação. Tivemos também 1 tutor que preferiria um curso presencial ou um site educacional tratando desta temática com informações atualizadas, as quais os ajudassem a adquirir mais conhecimentos sobre o tema.

Em uma pesquisa realizada por Gicieli e Gitahi (2012) foi observado que a formação e capacitação dos tutores foi essencial para a concretização e alcance dos objetivos institucionais 
almejados, assim as autoras recomendam que a capacitação seja de forma contínua e que possibilite "o desenvolvimento de competências que abarcam o conhecimento do conteúdo, as habilidades com a tecnologia, o manejo no ambiente virtual e atitudes de receptividade, interação, flexibilidade e motivação ao aluno virtual [...]” (GICIELI e GITAHI, 2012, p.580).

Podemos, a partir de todos os dados analisados verificar a necessidade de um constante investimento em formação adequada e continuada para os profissionais da EAD, e neste sentido, diante das responsabilidades e atribuições do tutor, compete também às "instituições de ensino desenvolver programas de capacitação de tutores, inclusive para o uso das ferramentas de tutoria, e que esses programas sejam oferecidos continuamente" (MAIA e MATTAR, 2007, p. 92).

\section{CONSIDERAÇÕES FINAIS}

O uso de MED na EAD é uma estratégia essencial para os estudantes durante o processo de ensino aprendizagem, pois com um bom material disponível será possível obter orientações, desenvolver a autonomia, construir conhecimentos, e conseguir relacionar a base teórica estudada com a execução das atividades práticas no âmbito profissional, permitindo assim o desenvolvimento de habilidades essenciais para um bom desempenho acadêmico e profissional.

Assim, perante o contexto tecnológico em que vivemos atualmente, a temática que versa sobre a utilização dos materiais digitais na EAD se torna imprescindível, visto que neste processo educativo é importante que utilizemos instrumentos que visem o desenvolvimento do aluno superando as dificuldades técnicas e pedagógicas existentes, pois o uso adequado da tecnologia aliado á fatores pedagógicos pode favorecer o processo de aprendizagem dos estudantes.

Considerando a importância que os materiais digitais têm no processo de ensino aprendizagem na EAD, e os desafios que os educadores ainda possuem para utilização destes materiais em suas metodologias, esta pesquisa se propôs a analisar os materiais educacionais digitais sob a visão dos tutores, investigando o uso, as possibilidades, limitações e apropriações pelos tutores do curso técnico em administração do IFPI em relação aos MED.

Inicialmente, destacamos que todos os tutores são unânimes quanto a afirmar ser importante o uso dos materiais digitais no processo de ensino aprendizagem na EAD, assim como todos os tutores consideram necessário que seja proporcionado instruções/orientações em relação ao uso dos MED, demonstrando a necessidade de fomentar discussões e atitudes neste campo do saber.

Também podemos inferir, que conforme os dados coletados, os docentes (autores ou pesquisadores) são os principais responsáveis pela escolha, análise, produção e disponibilização dos MED, dos cursos, porém os tutores também podem complementar os materiais de acordo 
com a verificação da necessidade da turma, contudo, observamos que dentro da amostra pesquisada apenas um tutor busca complementar os materiais disponibilizados, porém todos os tutores afirmaram conhecer outros MED e que gostariam de utilizá-los, mas acreditam que a baixa estrutura de internet das localidades não permitiria a exploração de outros materiais.

As possibilidades de uso dos materiais digitais são bem mais amplas do que as tradicionalmente utilizadas, e podem fazer uso de animações, simulações, áudios (podcast, música, audiobook), softwares, aplicativos, jogos educacionais, mapas mentais, hipertextos, dentre vários outros. Neste caso podemos concluir que existem muitas possibilidades de MED ainda a serem exploradas na EAD do IFPI, mas que também existem algumas limitações quanto a esse quesito.

Essa dificuldade, da diversificação na utilização de materiais, observada na EAD do IFPI, pode ser justificada pela pouca capacitação proporcionada aos professores e tutores, visto que significativa parcela dos tutores não possuem formação para atuação na $\mathrm{EAD}$, e muito menos para utilização de materiais digitais.

Dessa forma, podemos concluir que se torna necessário iniciativa das Instituições de ensino em frequentemente analisarem como seus educadores estão utilizando os materiais digitais no ambiente educativo e o quão estão preparados para usarem estas tecnologias, para que assim possam fazer, quando necessário, intervenções planejadas, que objetivem melhorar o conhecimento destes profissionais, capacitando-os e incentivando-os a aperfeiçoarem e agregarem valor ao uso dos materiais educacionais digitais no processo de ensino-aprendizagem em todas as modalidades da educação.

Portanto, com esta pesquisa ficou evidenciada a necessidade de melhorar a eficiência no uso dos MED e de orientar e preparar melhor os tutores na produção e escolha dos materiais digitais a serem utilizados nos cursos de EAD do IFPI, demonstrou ainda que não adianta apenas utilizar materiais digitais, mas que também é necessário oferecer materiais que sejam acessíveis e que tenham um nível de excelência de qualidade, coadunando com a missão do IFPI que é "promover uma educação de excelência, direcionada as demandas sociais".

\section{REFERÊNCIAS}

ALMEIDA, M. E. B. Educação à distância na internet: abordagens e contribuições dos ambientes digitais de aprendizagem. Educação e Pesquisa, São Paulo, v.29, n.2, p. 327-340, jul./dez. 2003. Disponível em: < http://www.scielo.br/pdf/ep/v29n2/a10v29n2.pdf >. Acesso em: 15 jan. 2016.

AMARILLA FILHO, P.. Educação à distância: uma abordagem metodológica e didática a partir dos ambientes virtuais. Educação em Revista, v. 27, n. 2, p. 41-72, 2011. 
BEHAR, P. A. (Orgs.) Modelos Pedagógicos em Educação à Distância. Porto Alegre: Artmed, 2009, 316 p.

CANTINI, M. C. et al. O desafio do professor frente às novas tecnologias. In: II Congresso Nacional de Educação, 2006, Paraná, Anais. Pontifícia Universidade Católica do Paraná, (PUCPR), 2006 p. 875-883. Disponível em:

<http://www.pucpr.br/eventos/educere/educere2006/anaisEvento/docs/CI-081-TC.pdf> Acesso em: 12 Mai. 2016.

CERVO, A. et al. Metodologia Cientifica. 6. Ed. São Paulo: Pearson, 2007, 176 p.

CORRÊA, M. A.. Os materiais didáticos como recursos fundamentais de potencialização da qualidade do ensino e aprendizagem na ead. E-Tech, Florianópolis, v. 6, n. 1, p.125-140, 2013.

CUNHA, R. M. et al. Os recursos tecnológicos como potencializadores da interdisciplinaridade no espaço escolar. In: The 4th International Congress on University-Industry Cooperation, Tabauté Anais. University of Taubate (UNITAU), 2012. Disponível em: < http://www.unitau.br/unindu/artigos/pdf571.pdf> Acesso em: 12 Dez. 2015.

FALKEMBACH, G.A. M. Concepção e Desenvolvimento de Material Educativo Digital. Revista Novas Tecnologias na Educação, maio. 2005. Disponível em:

< http://seer.ufrgs.br/renote/article/download/13742/7970> Acesso em: 10 dez. 2015.

FARIAS, S. C. O Audiolivro e sua contribuição no processo de disseminação de informações e na inclusão social. Revista Digital de Biblioteconomia e Ciência da Informação. Campinas, v.10, n.1, p.31-52, jul./dez. 2012. Disponível em: < http://periodicos.sbu.unicamp.br/ojs/index.php/rdbci/article/view/1895> Acesso em: 12 dez. 2015.

KENSKI, V. M. Educação e tecnologias: o novo ritmo da informação. Campinas, SP: Papirus, 2007, 141 p.

KENSKI, V. M. Tecnologia e ensino presencial e a distância. Campinas, SP: Papirus, 2003, 157 p.

LEITZKE, V.; D. et al. Desafios de ser tutor num curso à distância. Novas Tecnologias na Educaşão, v. 6 n. 1, p.1-5, Julho, 2008. Disponível em:

<http://seer.ufrgs.br/renote/article/viewFile/14641/8554> Acesso em: 20 jan. 2015.

LEKA, A. R.; GRINKRAUT, M. L. A utilização das redes sociais na educação superior. Revista Primus Vitam, $n^{\circ} 7-2^{\circ}$ semestre de 2014, p 1-13. Disponível em:

$<$ http://mackenzie.br/fileadmin/Graduacao/CCH/primus vitam/primus 7/aline.pdf $>$. Acesso em: 15 dez. 2016.

LITTO, F. M. Aprendizagem a distância. São Paulo: Imprensa Oficial, 2010, 98 p.

MAIA, C.; MATTAR, J. A. ABC da EAD: A educação à distância hoje. São Paulo: Editora Pearson, 2007, 138 p.

MARTINS, H. H.T. S. Metodologia qualitativa de pesquisa. Revista Educação e Pesquisa, São Paulo, v.30, n.2, p. 289-300, mai/ago. 2004. Disponível em:

< http://www.scielo.br/pdf/ep/v30n2/v30n2a07.pdf> Acesso em: 29 Abr. 2015. 
MARCONI, M. A.; LAKATOS, E. M. Fundamentos de Metodologia Científica. 7. ed. São Paulo: Atlas, 2010, 315 p.

MILL, D. R. S. et al. Polidocência na Educação à Distância. São Carlos: EdUFSCar, 2010, 1868Kb, ePUB. Disponível em:

$<$ https://play.google.com/books/reader?id=EMR9BAAAQBAJ\&printsec=frontcover\&output Ereader\&hl=pt BR\&pg=GBS.PA4.w.11.0.3 >Acesso em 10.Nov. 2016.

MINATTI, Z.D. et al. A formação do professor para atuação em EAD nos cursos de pedagogia de Santa Catarina. In: Seminário de Pesquisa em educação da região sul, 2012. Disponível em: $<$ http://www.portalanpedsul.com.br/admin/uploads/2012/Formacao de Professores/Trabalh o/05 $52 \quad 34$ 1791-7176-1-PB.pdf $>$. Acesso em: 15 Mai. 2016.

MORAN, José Manuel et al. Novas tecnologias e mediação pedagógica. 6. ed. Campinas: Papirus, 2000, $173 \mathrm{p}$.

RICIERI, M.; GITAHY, R. R.C. A importância da formação de tutores para sua atuação na educação à distância. Colloquium Humanarum, vol. 9, n. Especial, jul-dez, 2012.

SEVERINO, A. J. Metodologia do Trabalho Científico. 23. ed. rev. e atual. São Paulo: Cortez, 2007, $302 \mathrm{p}$.

SCHLOSSER, R. L. A atuação dos tutores nos cursos de educação a distância. Colabor@ - Revista Digital da CVA - Ricesu. v.6, n.22, fev.2010.

SOUZA, D. S. R. O uso dos Materiais educacionais digitais: limitações, potencialidades e apropriação, 2016, 136 p. Dissertação. Programa de Pós Graduação em Tecnologia e Gestão em Educação a distância. Universidade Federal Rural do Pernambuco

TORI, R. Educação sem distância: as tecnologias interativas na redução de distâncias em ensino e aprendizagem. São Paulo: Senac São Paulo, 2010, 254 p.

WOLYNEC, E. Conectado, o profissional do século 21 é a solução para muitas empresas! TECHNE, 2006, p 1-2. Disponível em: < https://www.techne.com.br/artigos/Univem Setembro2006.pdf> Acesso em 12 set. 2016. 